\title{
HE4 and Ovarian Cancers: New Era of Diagnosis
}

\author{
Mohamed Madi ${ }^{1}$, Fouad Ibrahim ${ }^{1}$, Inas A. Yahea ${ }^{2}$, Ahmed G. Elsayed ${ }^{3}$, Laila M. Elgendy ${ }^{4}$, \\ Khaled M. Omran ${ }^{5}$ \\ ${ }^{I}$ Faculty of public health, Benghazi University, Libya \\ ${ }^{2}$ Faculty of medicine, Gynecology and Obstetric Department, Tobruk University, Libya \\ ${ }^{3}$ Tobruk Medical Center, Pathology Department, Libya \\ ${ }^{4}$ Tobruk Medical Center, Biochemistry Department, Libya \\ ${ }^{5}$ Fculty of medicine, Medicine Department, Tobruk University, Libya
}

*Corresponding Author: Mohamed Madi, Faculty of public health, Benghazi University, Libya

\begin{abstract}
Introduction: Ovarian cancer is the 5th worldwide leading cause of death of women due to cancer. In more than $70 \%$ of cases, it is diagnosed at late stages. The prognosis for ovarian cancer is poor, with $46 \%$-year survival rate.Human Epididymis Protein 4 (HE4) is a new biomarker which has been currently evaluated for diagnosing ovarian malignant tumors.
\end{abstract}

Aim of the work: To study the prevalence and clinical significance of HE4 expression and its association with clinic pathological features of ovarian carcinomain Tobruk-Libya

Patients, Materials and Methods: The study group included 23 selected cases of ovarian cancers, diagnosed at Pathology department of Tobruk Medical Center, Libya, between 2016 and 2019. All patients were surgically treated and underwent total hysterectomy with bilateral salpingio-oopherectomy. The selection process was based on the clinical, radiological and histological criteria for diagnosis of ovarian cancers. Other clinic pathological data (age, tumor size, laterality and lymph node metastasis) were extracted from medical files.Serum samples were kept frozen until used to measure HE4.

Results: The mean age of the patients at initial surgery was 49.5 years (range, 31-68 years). 12 cases of the tumours were papillary serous cystadenocarcinoma (52.2\%); 7 cases were endometrioid carcinoma $(30.4 \%)$ and 4 cases were mucinous cystadenocarcinoma (17.4\%). Tumor size ranged between 8 and $17 \mathrm{~cm}$, with a mean of $12.5 \mathrm{~cm}$. Bilaterality was present in 9 cases (39.1\%) while 14 cases (60.9\%) were unilateral. Lymph nodes metastasis were present in 6 cases $(26.1 \%)$ and 17 cases $(73.9 \%)$ shows no lymph nodes metastasis. Analysis of HE4 expression was done in all cases. Ten cases of papillary serous cystadenocarcinoma (83.3\%) showed high HE4 serum level while only 2 cases (16.7\%) showed normal HE4 serum level. Six cases of endometriosis carcinoma (85.7\%) showed high HE4 serum level while only 1 case (14.3\%) showed normal HE4 serum level. Only one case of Mucinous cystadenocarcinoma (25\%) showed high HE4 serum level while 3 cases (75\%) showed normal HE4 serum level.

Conclusion: HE4can be used as diagnostic and prognostic marker useful for ovarian carcinoma with the well-known clinicopathological prognostic factors.

Keywords: HE4; tumor marker; ovarian cancer

\section{INTRODUCTION}

Cancer is a global health problem associated with increasing mortality rates, in-spite of advances in diagnostic and therapeutic approaches [1]. Several pathological parameters and specific blood tumor markers have been proposed as predictive prognostic factors in cancer $[2,3]$. However, the high incidence of cancer-related deathsindicates a need for reliable and efficient biomarkers for patient stratification andtreatment selection [4].
Ovarian cancer is the 5th worldwide leading cause of death of women due to cancer [5]. In more than $70 \%$ of cases, it is diagnosed at late stages. The prognosis for ovarian cancer is poor, with 46\%5-year survival rate [6]. The prognosis is closely related to the stage at diagnosis: survival rate of $>70 \%$ after 5years for stage I or II, survival rates between 20 and $40 \%$ for stage III or IV [7, 8].

Concerning laboratory exams, several tumor biomarkers have been evaluated. The 
Carbohydrate Antigen 125(CA125) was first described in the early 1980's [9].CA 125 is a widely used tumor marker for diagnosis and monitoring of ovarian cancer, but is not increased in some histological types of ovarian cancer [10]. It also has a high false positive rate in benign gynecological diseases such as ovarian cysts and uterine myomas [11].Therefore, CA 125 alone is not sufficient for screening and differential diagnosis of ovarian cancer [12]. Given these circumstances, many studies have introduced human epididymis protein 4 (HE4) as a new tumor marker to help diagnose ovarian cancer [13-15].

Human Epididymis Protein 4 (HE4) is a new biomarker which has been currently evaluated for diagnosing ovarian malignant tumors [16]. It is a glycoprotein belonging to the family of whey acidic four-disulfide core proteins, accounting for its alternative name of WFDC2 and the larger protein family called "WAP" for whey acidic proteins. The main genes coding for the WAP proteins are mainly located on chromosome 20q12-13.1 [17].Present in whey, these proteins are called WAP, which is composed of around 50 amino acids, and its biological function has not yet been completely identified [18].HE4 has been approved by the US Food and Drug Administration as a new tumor marker for the diagnosis of early stage ovarian cancer [19].

Due to increased incidence of ovarian cancers in Tobrouk, Libya, we were able to collect a cohort of 23ovarian cancers with follow up information. In this project we utilized this patient collection to investigate prevalence and clinical significance of HE4 expression in serum of patients with ovarian cancers.

\section{Patients, Materials and Methods}

The present study is a retrospective study.

The study group included 23 selected cases of ovarian cancers, diagnosed at Pathology department of Tobrouk Medical Center, Libya, between 2016 and 2019. All patients were surgically treated and underwent total hysterectomy with bilateral salpingiooopherectomy. The selection process was based on the clinical, radiological and histological criteria for diagnosis of ovarian cancers.

Other clinic pathological data (age, tumor size, laterality and lymph node metastasis) were extracted from medical files.

One sample was taken during diagnosis and before surgery. Two more samples were taken from patients with diagnosed ovarian cancers who underwent surgery. The second sample was drawn one week and the third sample was drawn one month postoperatively.

Serum samples were kept frozen until used to measure HE4. This tumor marker was measured in all patients with ovarian cancers for diagnosis and after surgery and treatment for follow up, using Cobas e411 (Roche).

\subsection{Processing Procedures}

Five $\mathrm{mL}$ blood was collected from all females and transferred to the laboratory. After the clotting, the blood samples were centrifuged. The serum was transferred to another tube and stored at $-20^{\circ} \mathrm{C}$ until use. HE4 was measured using Cobas e411 (Roche). Values $\geq 95 \mathrm{pmol} / 1$ were considered abnormal.

\subsection{Statistical Analysis}

- The collected data were coded then entered and analyzed using the SPSS version 22 (Statistical package for social science).

- Descriptive statistics was done for categorical variables by frequency and percentage, and for numerical variables in the form of mean and standard deviation (mean $\pm \mathrm{SD}$ ).

- Suitable statistical tests of significance were used:

- Chi-Square $(\chi 2)$ test for categorical data

- P-values equal to or less than 0.05 were considered statistically significant.

\section{Results}

\subsection{Clinicopathological Features}

The details of 23 patients selected for analyses are as follows. The mean age of the patients at initial surgery was 49.5 years (range, 31-68 years). 12 cases of the tumours were papillary serous cystadenocarcinoma(52.2\%); 7 cases were endometriosis carcinoma $(30.4 \%)$ and 4 cases were mucinous cystadenocarcinoma (17.4\%).Tumor size ranged between 8 and $17 \mathrm{~cm}$, with a mean of $12.5 \mathrm{~cm}$. Bilaterality was present in 9 cases $(39.1 \%)$ while 14 cases $(60.9 \%)$ were unilateral. Lymph nodes metastasis were present in 6 cases $(26.1 \%)$ and 17 cases $(73.9 \%)$ shows no lymph nodes metastasis.

\subsection{HE4 Expression}

Analysis of HE4 expression was done in all cases. Ten cases of papillary serous cystadenocarcinoma $(83.3 \%)$ showed high HE4serum level while only 2 cases (16.7\%) showed normal HE4serum level. Six cases of endometrioid carcinoma (85.7\%) showed high 
HE4serum level while only 1 case $(14.3 \%)$ showed normal HE4serum level. Only one case of Mucinous cystadenocarcinoma (25\%) showed

Table1: HE4 expression in different subtypes of ovarian carcinomas.

\begin{tabular}{|l|c|c|c|}
\hline \multirow{2}{*}{ Histological subtypes } & Elevated & Normal & Total \\
\cline { 2 - 4 } & 10 & 2 & 12 \\
\hline Papillary serous cystadenocarcinoma & 6 & 1 & 7 \\
\hline Endometrioid carcinoma & 1 & 3 & 4 \\
\hline Mucinous cystadenocarcinoma & 17 & 6 & 23 \\
\hline Total & \multicolumn{2}{|c|}{ HE4 exprion } & \\
\hline
\end{tabular}

\subsection{Correlations between HE4 Expression and Clinicopathological Features}

Univariate analysis revealed significant differences between HE4 expression (elevated versus normal) and histopathological subtype

Table2: Relationship between HE4 expression and clinicopathological features.

\begin{tabular}{|c|c|c|c|}
\hline \multirow{2}{*}{ Clinicopathological features } & \multicolumn{2}{|c|}{ HE4expression } & \multirow{2}{*}{ Chi-square test } \\
\hline & Elevated 17 & Normal 6 & \\
\hline \multicolumn{4}{|l|}{ Age at initial surgery (median) } \\
\hline$<50$ ( 8 cases $)$ & $6(75 \%)$ & $2(25 \%)$ & \multirow{2}{*}{$P=0.931$} \\
\hline$\geq 50(15$ cases $)$ & $11(73.3 \%)$ & $4(26.7 \%)$ & \\
\hline \multicolumn{4}{|l|}{ Tumor size (median) } \\
\hline$<12.5$ ( 6 cases $)$ & $5(83.3 \%)$ & $1(16.7 \%)$ & \multirow{2}{*}{$P=0.541$} \\
\hline$\geq 12.5$ ( 17 cases $)$ & $12(70.6 \%)$ & $5(29.4 \%)$ & \\
\hline \multicolumn{4}{|l|}{ Histopathological subtype } \\
\hline Papillary serous cystadenocarcinoma ( 12 cases) & $10(83.3 \%)$ & $2(16.7 \%)$ & \multirow{3}{*}{$P=0.491 *$} \\
\hline Endometrioid carcinoma( 7 cases $)$ & $6(85.7 \%)$ & $1(14.3 \%)$ & \\
\hline Mucinous cystadenocarcinoma (4 cases) & $1(75 \%)$ & $3(25 \%)$ & \\
\hline \multicolumn{4}{|l|}{ Laterality } \\
\hline Unilateral (14 cases) & $10(71.4 \%)$ & $4(28.6 \%)$ & \multirow{2}{*}{$P=0.735$} \\
\hline Bilateral ( 9 cases) & $7(77.8 \%)$ & $2(22.2 \%)$ & \\
\hline \multicolumn{4}{|l|}{ Lymph node metastasis } \\
\hline +ve ( 6 cases) & $5(83.3 \%)$ & $1(16.7 \%)$ & \multirow{2}{*}{$P=0.541$} \\
\hline -ve (17 cases) & $12(70.6 \%)$ & $5(29.4 \%)$ & \\
\hline
\end{tabular}

$* p$-value $<0.05$ was considered to be statistically significant.

\section{DISCUSSION}

Ovarian cancer has a high mortality rate and represents fifth leading cause of cancer-related death in women. In ovarian cancer diagnosis, therefore, all efforts are directed towards finding a new, better biomarker that would be more specific to this disease. In the present practice, the most commonly used ovarian cancer biomarker is CA125. More recently, from all of the potential biomarkers tested, the HE4 had the best results for clinical use [20].

HE4 is a new tumor biomarker, which has been a subject of intense research in recent years. HE4, originally discovered by Kirchhoff in the human distal epididymal epithelial cells, [21] is located on chromosome 20 at 20q12-13 and contains fiveexons and four introns [22]. It contains a gene encoding proteindomains that have homology with whey acidic protein, by which the product encoded is mainly protease
(Table 2). No significant correlation was found between HE4 expression and age, tumor size, tumor laterality, as well as lymph node metastases (Table 2). high HE4serum level while 3 cases $(75 \%)$ showed normal HE4serum level (Table 1). 
specificity of $86 \%$ for HE4 [27].These data, in accordance with those reported in a recent Italian multicentre study included 387 patients, showed that HE4 for diagnosing ovarian epithelial cancer appeared more reliable than CA125 [28].

Park et al also reported that the levels of CA 125 and HE4 increased in various benign gynecological diseases, especially in adenomyosis. The increase in CA125 and HE4 concentrations differed according to disease, and an increase in CA 125 was more frequent than an increase in HE4 in benign conditions. Therefore, it is considered that the specificity of HE4 is higher than that of CA 125. Furthermore, the degrees of increase in the levels of these tumor markers also varied according to the pathologic type of ovarian cancer [29, 30]. In this study, the level of HE4 was high in serous carcinoma and endometriosis carcinoma, whereas the level of HE4 was low in mutinous carcinoma.

The clinic pathological characteristics and HE4 expression relationship in our results shows no significant association with age, tumor size, laterality and lymph node metastasis. However, there is significant association with histopathological subtypes. Unfortunately, there is no much studies to discuss with these results.

\section{Limitations of the Study}

Our study has some limitations. First, a small sample size was used to identify the value of HE4 expression in ovarian carcinomas because of the short study period. Second, there is no follow-up documents of the patients and this study is designed and performed recently.

\section{CONCLUSiON}

Our results show that HE4 is a useful biomarker in diagnosis and follow up of most of ovarian carcinomas, with the well-known clinic pathological prognostic factors. Definitely, we are attentive that further, larger researches are compulsory to validate HE4 as independent diagnostic, prognostic or predictive factor in ovarian carcinoma. A long-term follow-up study will be necessary to identify the clinical value of HE4 expression in ovarian carcinoma.

\section{REFERENCES}

[1] Ferlay J, Soerjomataram I, Dikshit R, Eser S, Mathers C,Rebelo M, Parkin D, Forman D, Bray F. Cancer incidence and mortality worldwide: sources, methods and major patterns in GLOBOCAN 2012. Int J Cancer. 2015; 136(5):E359-E386.
[2] Abe S, Kawai K, Ishihara S, Nozawa H, Hata $\mathrm{K}$, Kiyomatsu T, Tanaka T, Watanabe $\mathrm{T}$. Prognostic impact of carcinoembryonicantigen and carbohydrate antigen 19-9 in stage IV colorectal cancer patients after $\mathrm{R} 0$ resection. J Surg Res. 2016; 205(2):384-392.

[3] Jiang H, Tang E, Xu D, Chen Y. Development and validation of nomogramsfor predicting survival in patients with non-metastatic colorectal cancer.Oncotarget. 2017; 8(18): 298 57-29864.

[4] Cong Dai, Yi Zheng,Yuanjie Li, Tian Tian, MengWang, Peng Xu, YujiaoDeng, Qian Hao, YingWu, Zhen Zhai, ZhijunDai, Jun L yu. Prognostic values of HE4 expression in patientswith cancer: a meta-analysis. Cancer Management and Research 2018:10 4491-4500.

[5] Jemal A, Siegel R, Ward E, Hao Y, Xu J, Murray T, Thun M. Cancer statistics, 2008. CA Cancer J Clin.2008; 58:71-96.

[6] Chan JK, Teoh D, Hu JM, Shin JY, Osann K, Kapp DS. Do clear cell ovarian carcinomas have poorerprognosis compared to other epithelial cell types? A study of 1411 clear cellovarian cancers. Gynecol Oncol. 2008; 109: 370-6.

[7] Heintz APM, Odicino F, Maisonneuve P, Quinn MA, Benedet JL, Creasman WT, Ngan HYS, Pecorelli S, Beller U. Carcinoma of the ovary. FIGO26th annual report on the results of treatment in gynecological Cancer. IntJ Gynaecol Obstet. 2006; 95(Suppl 1):S161-92.

[8] Zeppernick F, Meinhold-Heerlein I. The new FIGO staging system forovarian, fallopian tube, and primary peritoneal cancer. Arch Gynecol Obstet.2014; 290:839-42.

[9] Vincent Dochez, Hélène Caillon, Edouard Vaucel, Jérôme Dimet, Norbert Winer, Guillaume Ducarme. Biomarkers and algorithms for diagnosis ofovarian cancer: CA125, HE4, RMI andROMA, a review. Journal of Ovarian Research.2019; 12:28.

[10] Rosen DG, Wang L, Atkinson JN, Yu Y, Lu KH, Diamandis EP, Hellstrom I, Mok SC, Liu J, Bast RC. Potential markers that complement expression of CA125 in epithelial ovarian cancer. Gynecol Oncol. 2005; 99(2):267-277.

[11] Maggino T, Gadducci A, D’Addario V, Pecorelli S, Lissoni A, Stella M, Romagnolo C, Ferdeghini M, Zucca S, Trio D, Trovo S. Prospective multicenterstudy on CA 125 in postmenopausal pelvic masses. Gynecol Oncol.1994; 54(2):117-123.

[12] Kobayashi H, Yamada Y, Sado T, Sakata M, Yoshida S, Kawaguchi R, Kanayama S, Shigetomi H, Haruta S, Tsuji Y, Ueda S, Kitanaka T. A randomized study of screeningfor ovarian cancer: a multicenter study in Japan. Int J GynecolCancer. 2008; 18(3):414-420. 
[13] Hellstrom I, Hellstrom KE. SMRP and HE4 as biomarkers for ovariancarcinoma when used alone and in combination with CA125 and/oreach other. Adv Exp Med Biol. 2008; 622:15-21.

[14] Moore RG, Brown AK, Miller MC, Skates S, Allard WJ, Verch T, Steinhoff M, Messerlian G, Disilvestro P, Granai CO, Bast RC. The use of multiple noveltumor biomarkers for the detection of ovarian carcinoma in patientswith a pelvic mass. Gynecol Oncol. 2008; 108(2):402-408.

[15] Moore RG, Jabre-Raughley M, Brown AK, Robison KM, Miller MC, Allard WJ, Kurman RJ, Bast RC, Skates SJ. Comparison of anovel multiple marker assay vs the risk of malignancy index forthe prediction of epithelial ovarian cancer in patients with a pelvicmass. Am J Obstet Gynecol. 2010; 203(3):228. E221-226.

[16] Hellström I, Raycraft J, Hayden-Ledbetter M, Ledbetter JA, Schummer M, Mclntosh M, Drescher C, Urban N, Hellström KE. The HE4 (WFDC2) proteinis a biomarker for ovarian carcinoma. Cancer Res. 2003; 63:3695-700.

[17] Bouchard D, Morisset D, Bourbonnais Y, Tremblay GM. Proteins with wheyacidic-protein motifs and cancer. Lancet Oncol. 2006; 7:167-74.

[18] Hennighausen LG, Sippel AE. Mouse whey acidic protein is a novel memberof the family of "four-disulfide core" proteins. Nucleic Acids Res. 1982; 10:2677-84.

[19] Chang X, Ye X, Dong L, Cheng H, Cheng Y, Lirong Z, Liao Q, Zhao Y, Tian L, Fu T, Chen J, Cui H. Human epididymis protein 4 (HE4)as a serum tumor biomarker in patients with ovarian carcinoma. Int JGynecol Cancer. 2011; 21(5):852-858.

[20] Moore GR, Miller MC, Eklund EE, Lu HK, Bast CR.Jr, Lambert-Messerlian G. Serum Levels of the Ovarian Cancer BiomarkerHE4 are decreased in Pregnancy and Increase with Age,Am J Obstet. 2012 Apr; 206(4): 349.

[21] Kirchhoff C, Habben I, Ivell R, Krull N. A major human epididymisspecificcDNA encodes a protein with sequence homology to extracellularproteinase inhibitors. Biol Reprod. 1991; 45(2):350-357.

[22] Bingle L, Singleton V, Bingle CD. The putative ovarian tumour markergene HE4 (WFDC2), is expressed in normal tissues and undergoescomplex alternative splicing to yield multiple protein isoforms. Oncogene.2002; 21(17):2768-2773.

[23] Clauss A, Lilja H, Lundwall A. A locus on human chromosome 20contains several genes expressing protease inhibitor domains withhomology to whey acidic protein. Biochem J. 2002; 368(Pt 1):233-242.

[24] Jelic S, ESMO Guidelines Working Group. Hepatocellular carcinoma: ESMO clinical recommendations for diagnosis, treatment and follow-up. Ann Oncol. 2009; 20: 41-5.

[25] Drapkin R, von Horsten HH, Lin Y,Mok SC, Crum CP, Welch WR, Hecht JL. Human epididymis protein 4 (HE4)is a secreted glycoprotein that is overexpressed by serous andendometrioid ovarian carcinomas. Cancer Res. 2005; 65:2162-9.

[26] Shridhar V, Lee J, Pandita A, Iturria S, Avula R, Staub J, Morrissey M, Calhoun E, Sen A, Kalli K, Keeney G, Roche P, Cliby W, Lu K, Schmandt R, Mills GB, Bast RC, James CD, Couch FJ, Hartmann LC, Lillie J, Smith DI. Genetic analysis of early- versus late-stage ovarian tumors. Cancer Res. 2001; 61:5895-904.

[27] Yanaranop M, Anakrat V, Siricharoenthai S,Nakrangsee S, Thinkhamrop B. Is the risk of ovarian malignancy algorithm better than other tests for predicting ovarian malignancy in women with pelvic masses? GynecolObstetInvestig. 2017; 82:47-53.

[28] Romagnolo C, Leon AE, Fabricio ASC,Taborelli M, Polesel J, Pup LD, Steffan A, Cervo S, Ravaggi A, Zanotti L, Bandiera E, Odicino FE, Scattolo N, Squarcina E, Papadakis C, Maggino T, Gion M. HE4, CA125 and risk of ovarian malignancy algorithm (ROMA) as diagnostic tools for ovarian cancer in patients with a pelvic mass: an Italian multicenter study. Gynecol Oncol.2016; 141:303-11.

[29] Park Y, Kim Y, Lee EY, Lee JH, Kim HS. Reference ranges for HE4 and CA125 in a large Asian population by automated assays and diagnostic performances for ovarian cancer. Int J Cancer. 2012; 130(5):1136-1144.

[30] Park Y, Lee JH, Hong DJ, Lee EY, Kim HS. Diagnostic performances of HE4 and CA125 for the detection of ovarian cancer from patients with various gynecologic and nongynecologic diseases. Clin.Biochem. 2011; 44(10-11):884-888.

Citation: Mohamed Madi, Fouad Ibrahim, Inas A. Yahea, Ahmed G. Elsayed, Laila M. Elgendy, Khaled M. Omran. HE4 and Ovarian Cancers: New Era of Diagnosis. ARC Journal of Cancer Science. 2020; 6(2):01-05. DOI: dx.doi.org/10.20431/2455-6009.0602001.

Copyright: (C) 2020 Authors. This is an open-access article distributed under the terms of the Creative Commons Attribution License, which permits unrestricted use, distribution, and reproduction in any medium, provided the original author and source are credited. 